\title{
Management of paediatric illnesses by patent and proprietary medicine vendors in Nigeria
}

\author{
Emily Treleaven ${ }^{1,2}$, Jenny Liu', Lisa M. Prach ${ }^{1}$ and Chinwoke Isiguzo ${ }^{3 *}$
}

\begin{abstract}
Background: In Nigeria and elsewhere, informal drug sellers, or patent and proprietary medicine vendors (PPMVs), are a common source of care for children with malaria, diarrhoea, and pneumonia. However, their knowledge and stocking of recommended treatments for these common childhood illnesses are not well understood.

Methods: A census of PPMV shops was conducted in Kogi and Kwara states. A shop survey was conducted on a subset of 250 shops. Multivariate regression analysis was used to assess associations between shop worker characteristics and (1) knowledge of optimal treatments for malaria, diarrhoea, and pneumonia, and (2) stocking of essential medicines to treat these illnesses.

Results: From the census, $89.9 \%$ of shops stocked oral rehydration solution (ORS), while $61.1 \%$ of shops stocked artemisinin-based combination therapies and $72.2 \%$ of shops stocked amoxicillin. Stocking patterns varied by state, urban/rural location, and according to whether or not the shop was headed by someone with formal health training (e.g. having a professional health education degree). In multivariate analyses, selling drugs wholesale and participating in any training in the past year was associated with a higher likelihood of naming the correct treatment for malaria, and having formal health training was associated with stocking ORS. However, few other PPMV characteristics were predictive of correct knowledge of optimal treatments and stocking behaviour.
\end{abstract}

Conclusion: Many PPMVs lack the knowledge and tools to properly treat common childhood illnesses. PPMV knowledge and selling of essential medicines for these illnesses should be strengthened to improve child health in Nigeria.

Keywords: Malaria, Pneumonia, Diarrhoea, Nigeria, Private sector, Drug vendors, Integrated management of childhood illnesses, Community case management

\section{Background}

Pneumonia, diarrhoea, and malaria are the leading causes of child mortality in Nigeria, from which over one million children under five are estimated to die each year [1]. These conditions contribute 16.4, 18.7, and $20.1 \%$ of the total burden of disease, respectively [1]; thus, ensuring prompt and proper diagnosis and treatment for these illnesses is essential for reducing childhood morbidity and mortality [2].

Treatment guidelines in Nigeria and elsewhere recommend that children exhibiting signs of pneumonia, including coughing, fever, and rapid breathing, be seen by a health professional, and if properly diagnosed, prescribed amoxicillin in dispersible tablet form [3].

\footnotetext{
* Correspondence: cisiguzo@sfhnigeria.org

${ }^{3}$ Society for Family Health, No. 8 Port Harcourt Crescent, Area 11, Garki, Abuja, Nigeria

Full list of author information is available at the end of the article
}

Children diagnosed with uncomplicated malaria should be treated with artemisinin-based combination therapy (ACT) after, ideally, parasitological confirmation $[4,5]$. Children with diarrhoea should be given low-osmolarity oral rehydration solution (ORS) in combination with zinc tablets to reduce the duration and severity of fluid loss [6].

The Integrated Community Case Management (iCCM) strategy for childhood illnesses adopted by the Nigeria Ministry of Health (MOH) in 2014 aims to improve access to these treatments and provide referrals to formal care when necessary through community-based health workers or other resource persons [7]. The $\mathrm{MOH}$, in the early stages of implementing its iCCM strategy, defines iCCM resource persons as respected community members, aged 18 to 65 , and literate, and who are accessible and willing to participate [7]. Providers eligible to deliver iCCM include for-profit drug retailers, or patent and proprietary 
medicine vendors (PPMVs), who are often the first source of care for common health concerns and commodities $[8,9]$, including treatment for children under five with fever or cough [10]. With an estimated over 200,000 shops in Nigeria [11], PPMVs are highly accessible and are a particularly important access point for basic health services among rural and poor households $[8,12,13]$.

However, PPMV licensure does not require formal pharmacy training or a minimum level of education [14-16], which raises concerns about the quality of care that PPMVs provide. PPMV licensure is currently under review by the Pharmacy Council of Nigeria (PCN), and some PPMVs have formal medical training, such as nursing or pharmacy. PPMVs are permitted to sell prepackaged, over-the-counter drugs (e.g. ACT, ORS) but not prescription drugs (e.g. antibiotics) [17]. Past studies of PPMVs in Nigeria have found they may improperly identify and treat common childhood illnesses [18, 19], and that many PPMVs sell drugs and services beyond their legal scope of practice $[11,16]$. Because PPMVs are for-profit microenterprises, they are particularly responsive to what their customers ask of them [14, 20], which may lead to under-stocking and under-provision of low-demand products, such as zinc [21]. Despite their central role in delivering treatments for childhood illnesses [10]. Little is known about how PPMVs provide integrated disease management for children [22]. The few existing studies of PPMV practices around childhood illness focus almost exclusively on malaria [16, 23, 24], with only one study on childhood diarrhoea [25] and none on pneumonia [22].

Because of their abundance, accessibility, and eligibility as an iCCM provider, coupled with concerns over quality of care, this study of PPMV practices examines their stocking practices and knowledge for three common childhood illnesses, malaria, diarrhoea, and pneumonia, for which there is scant existing evidence. Specifically, this paper aims to describe PPMVs' stocking patterns of essential medicines to treat malaria, pneumonia, and diarrhoea, and assess associations between shop worker characteristics and knowledge and stocking of optimal treatments for these diseases. Understanding PPMVs' knowledge and stocking of malaria, pneumonia, and diarrhoea treatments in the context of iCCM scale-up in Nigeria is important as they are a primary point of care for sick children; implications for iCCM implementation are discussed.

\section{Methods}

\section{Data sources}

A census of all retail establishments selling drugs in Kogi and Kwara states was conducted from April to September 2013. Kogi and Kwara states were chosen to represent Nigeria's central region, with mixed populations by religion, socio-economic status, ethnicity, and mix of urban, peri-urban, and rural areas, in comparison to southern Nigeria, where a majority of studies in Nigeria are concentrated [24].

This census listing produced a database of 2,083 shops (1,088 in Kogi, 995 in Kwara), and collected limited information on shop owner and worker characteristics, and the types, doses, and brands of medicines stocked for malaria, pneumonia, and diarrhoea. From this listing, 250 shops (125 in each state) were selected for a survey that collected additional information on shop characteristics, services, and knowledge and practices of shop workers. The sub-sample included in the survey was not meant to be representative of the census, but to generate an analytical sample. Due to logistical challenges and security concerns of extended periods of stay in certain areas, the sub-sample was chosen through a modified stratified random sampling approach. In each state, shops within a $25-\mathrm{km}$ radius of the center of four urban or peri-urban hubs (ranging from 21 to 39 shops per hub) were randomly selected, stratified across urban, peri-urban, and rural locations (Kogi: Ayangba, Ida, Lokoja, and Okene; Kwara: Ajase-Ipo, Bode-Sadu, Ilorin, and Omu-Aran). In consultation with a geospatial expert, a $25-\mathrm{km}$ was determined to be sufficient to generate a difference in urban, peri-urban, and rural locations. If a shop could not be located (due to absent provider, closed shop, or incorrect address), the next closest shop was selected as a substitute (Kogi: 30 shops, Kwara: 24 shops) to preserve sample stratification, regardless of its inclusion on the census, and to account for shops that opened after the census was taken. All shops selected in the sampling process or identified as a substitute were eligible to participate.

\section{Data collection}

From Monday to Saturday in September and October 2013, one multi-lingual study surveyor was assigned to visit one shop per day. Upon arrival, the surveyor self-identified as working with a non-profit organization focused on health, and sought consent from the person in charge (79.2 \% shop owner, $6.8 \%$ manager, $13.2 \%$ apprentice, $0.8 \%$ other). Shop owners were not given advance notice. All shops located and approached for consent agreed to participate.

Surveyors administered the survey in the morning when customer traffic was typically low. Interruptions for attending to customers were permitted. The survey instrument was designed to collect information on shop owners' and workers' sociodemographic characteristics, self-reported knowledge and practices for treating childhood malaria, diarrhoea, and pneumonia, resources for drug and healthcare advice, and training. Participants were given a small gift for participation (wall clock valued at 500 Naira [ US\$3.13]). 


\section{Outcome measures}

Two outcome measures were analyzed in this paper: (1) correct knowledge of the most effective drug to treat malaria and diarrhoea; and (2) whether the shop stocked at least one effective drug for the treatment of malaria and diarrhoea. Due to the extremely low recognition and understanding of pneunomia among respondents, multivariate analyses of outcomes for pneumonia were not possible (see results). Further, diagnosis is excluded as an outcome because PPMVs are not legally allowed to perform diagnostic tests. Knowledge of the most effective drug to treat childhood malaria, diarrhoea, or pneumonia was coded as correct if the respondent answered with ACT, ORS, or amoxicillin, respectively. While other appropriate treatments exist for these illnesses, ACT, ORS, and amoxicillin were chosen because they are listed as optimal treatments under ICCM guidelines. Stocking of zinc for treatment of diarrhea is excluded as an outcome due to its extremely low prevalence in the study area. Respondents were asked about treatments for specific diseases and symptoms; where they provided brand names, responses were recoded to the type of medicine, such as "ACT" for "Coartem."

\section{Data analysis}

In bivariate analysis, differences in knowledge of most effective treatments, drug stocking, shop characteristics [state, location (urban, peri-urban, or rural), registration with the PCN, selling wholesale drugs, and offering tests or examinations to customers], and respondents' characteristics (age, sex, education, years of experience working at a drug shop, religion, proportion of household income from the shop, and participation in any type of training in the past year) between respondents with and without formal health training are examined. Respondents self-reporting health training as a doctor, nurse, midwife, pharmacist, laboratory technician, or community health extension worker (CHEW) were considered to have formal health training, while current or finished PPMV apprentices were considered not to have formal health training. In addition to retail sales, some PPMVs sell drugs wholesale to other PPMVs or pharmacies. Respondents self-reported whether they provide examinations or diagnostic tests, such as malaria rapid diagnostic tests or physical examinations. Respondents who reported that more than half of their household income was generated from the PPMV shop were coded as having the majority of their household income come from the shop.

For treatment knowledge and stocking outcomes, multivariate analyses were conducted using logistic regressions. It is important to note that too few respondents gave correct answers for pneumonia treatment, which precluded further multivariate analysis (see results). Covariates for
PPMV shop and worker characteristics were selected based on a priori hypotheses of determinants of knowledge and stocking practices and included those listed above. Analyses were conducted using STATA SE Version 13.1.

Interaction effects were tested to explore whether PPMVs with formal health training had significantly different knowledge or stocking practices if they were male, had more years of experience, or were located in an urban area. As none were significant, they are not included in the final analysis. Alternative categorizations of age, years of experience, and profession were examined to assess sensitivity, but resulting estimates did not change substantive findings. It is important to note that the Affordable Medicines Facility-malaria (AMFm) programme, an international subsidy on ACTs to increase its supply and affordability and reduce the use of non-recommended anti-malarials, which included a malaria and malaria training programme for participating providers, operated in the study area [20]. Selected retail outlets, including some larger PPMVs, participated in the AMFm programme as distributors, and many PPMVs were recipients of the subsidized retail products and training component. We explored the independent effect of AMFm inclusion, but, because participation in the AMFm program was not associated with our outcome measures, it is not included in the final analysis.

\section{Ethical considerations}

Ethical approval was obtained from the National Health Research Ethics Committee of Nigeria (NHREC/01/01/ 2007-05/09/2013). Surveyors obtained written informed consent from all persons in charge at selected shops.

\section{Results}

\section{Stocking patterns from the PPMV shop census}

A total of 1,088 PPMV shops in Kogi and 995 in Kwara were identified during the census. $33.3 \%$ of Kogi shops and $12.2 \%$ of Kwara shops participated in the AMFm programme. Figure 1 displays the stocking patterns for essential medicines across urban, peri-urban, and rural locations. In Kogi, stocking of any form of amoxicillin was higher in urban areas $(89.3 \%)$ compared to peri-urban $(80.9 \%)$ and rural $(63.5 \%)$ areas. In Kwara, the trend for amoxicillin stocking was reversed: $59.7 \%$ among urban PPMVs, increasing to $69.5 \%$ of peri-urban shops and $80.4 \%$ of rural shops. Although lower in Kwara, stocking of ACTs in Kogi and Kwara was highest in urban areas (80.3 and $61.9 \%$, respectively) compared to peri-urban (71.5 and $48.5 \%$, respectively) and rural (62.8 and $42.1 \%$, respectively) shops. Of the essential medicines, availability of ORS was highest overall, with $85.0 \%$ (urban Kwara) to $93.5 \%$ (rural Kogi) of PPMV shops stocking it. Less than $3 \%$ of all PPMVs stocked zinc tablets. Zinc stocking was 


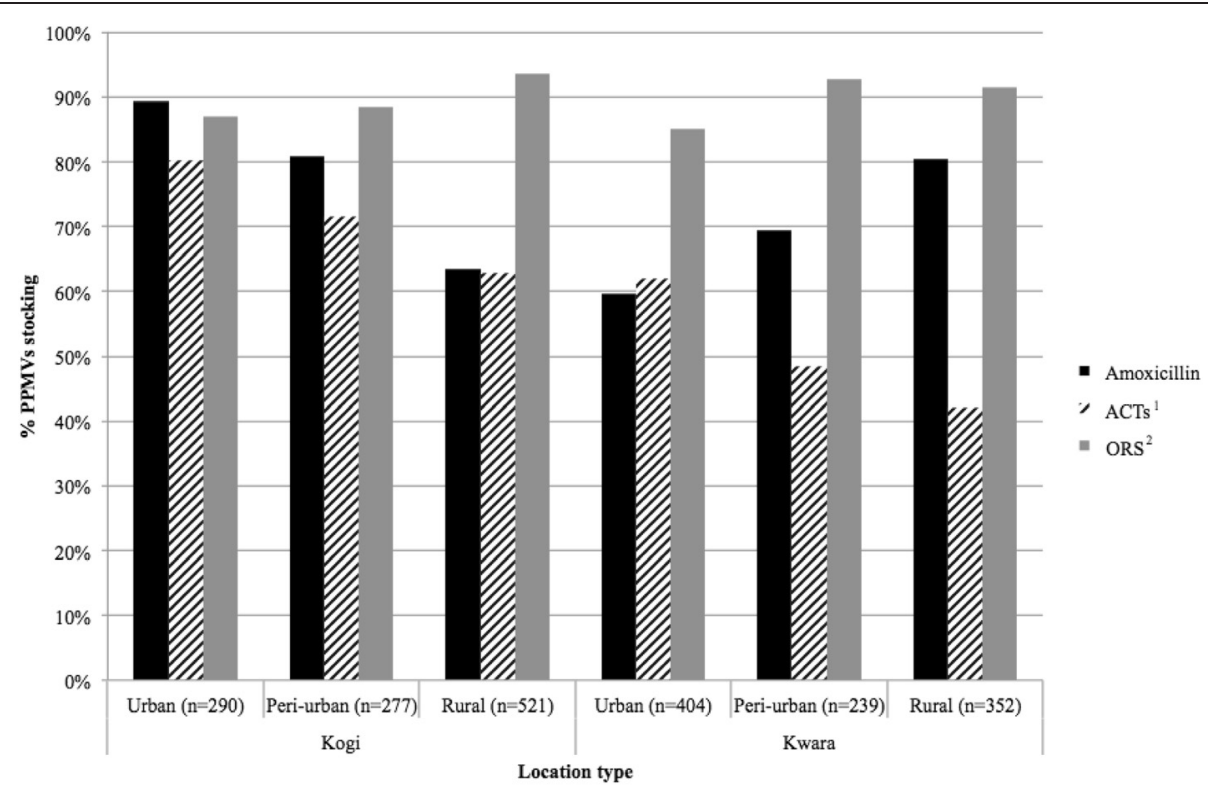

Fig. 1 Stocking of essential medicines by location at Kogi and Kwara PPMVs. The percentage of PPMVs $(n=2083)$ stocking different essential medicines for the treatment of childhood illnesses was plotted according to state and location type within state. Within each drug or commodity type, all brands and dosages are grouped together (Source: Census). ${ }^{1} \mathrm{ACT} s=$ artemisinin-based combination therapy ${ }^{2}$ ORS $=$ oral rehydration solution

highest in urban Kogi, $8.8 \%$, but fewer than $1 \%$ of PPMVs stocked zinc in urban Kwara.

Overall, $57.0 \%$ of PPMVs had some type of formal health training, of whom $30.4 \%$ were nurses or midwives, $21.5 \%$ CHEWs, $4.3 \%$ pharmacists, and $0.7 \%$ doctors.
Among shop owners and workers with formal health training, over three-quarters $(86.7 \%$ of doctors, $75.9 \%$ of nurses/midwives, $84.3 \%$ of CHEWs, and $79.3 \%$ of pharmacists) stocked amoxicillin, while only $68.2 \%$ of PPMVs without formal health training did so (Fig. 2). A

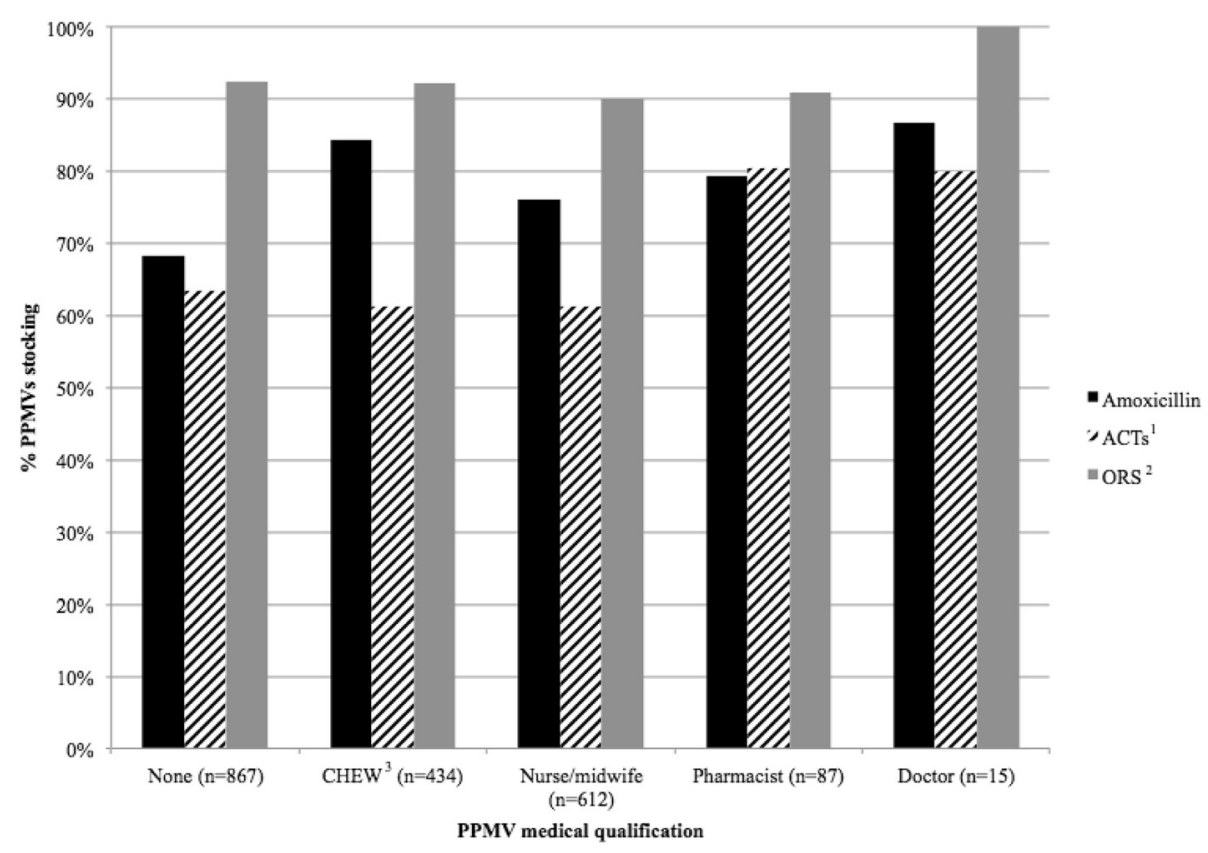

Fig. 2 Stocking of essential medicines by formal medical training at Kogi and Kwara PPMVs. The percentage of PPMVs $(n=2015)$ stocking different essential medicines for the treatment of childhood illnesses was plotted according to the shop owner's self-reported type of formal health training. Within each drug or commodity type, all brands and dosages are grouped together (Source: Census). ${ }^{1} \mathrm{ACT} s=$ artemisinin-based combination therapy ${ }^{2} \mathrm{ORS}=$ oral rehydration solution ${ }^{3} \mathrm{CHEW}=$ community health extension worker 
higher percentage of shop owners who were pharmacists or doctors stocked ACT (80.4 \% and $80.0 \%$, respectively), compared to PPMVs who were CHEWs (61.3\%), nurses/ midwives (61.3\%), and those without formal health training (63.3\%). Stocking of ORS was very high overall, with $100 \%$ of doctors and over $90 \%$ of all other shop owner types stocking it. Stocking of zinc was highest among nurses/midwives (12.7 \%) and pharmacists (8.5 \%), but was less than $3 \%$ of CHEWs and those without formal health training, and no doctors stocked zinc.

\section{Shop survey sample characteristics}

For the subset of PPMVs shops selected for the shop survey, basic characteristics of the shop and the person in charge are summarized in Table 1 . Overall, $21.2 \%$ of PPMVs in the shop survey had any formal health training. The percentage of PPMVs with formal health training differs between the census and the shop survey due to two reasons: (1) The random sampling frame employed in the shop survey had to be modified to accommodate logistical challenges and security risks; (2) Some shops enumerated from the census were not able to be located if they were no longer in business, and replacement shops may include new businesses that were newly operational since the census was taken. Limitations are discussed in the following section.

A majority of formally trained PPMVs were CHEWs (52.8\%), followed by nurses/midwives (34.0\%), laboratory technicians (7.6 \%), and pharmacists (5.7\%). Among PPMVs without health training, $67.7 \%$ had completed an apprenticeship; $32.3 \%$ were current PPMV apprentices or did not report any form of formal or informal training. In this sample, a higher percentage of PPMVs in Kwara had health training (60.4 \% versus $39.6 \%$ in Kogi), while PPMVs without formal health training were evenly distributed between the two states. A slightly higher proportion of health-trained PPMVs were in a rural area (47.2\% versus $20.8 \%$ and $32.1 \%$ in urban and peri-urban areas, respectively). Those without formal training were more evenly distributed across locations.

Over half of health-trained and untrained PPMVs were male (52.8 and $60.3 \%$, respectively). The mean (SD) age of health-trained respondents was nine years older than untrained respondents-40.0 years (12.3) compared to 31.0 years $(10.9)$, respectively $(p=0.000)$. A higher percentage of PPMVs were Christian than Muslim. Both educational attainment and experience working at a PPMV shop were significantly higher among respondents with health training than those without: $94.3 \%$ versus $23.4 \%$ with post-secondary education $(p=0.000)$, respectively; a mean (SD) of 16.7 years (11.2) of PPMV work experience versus 10.5 years $(8.2 ; p=0.000)$, respectively. Health-trained PPMVs were significantly more likely to offer tests or examinations to customers $(52.8 \%)$ than untrained PPMVs (30.3\%; $p=0.002)$. Differences between health-trained and untrained PPMV were not observed for respondents who reported that more than half of their household income came from the shop, that their shop sold drugs wholesale, or that the shop was registered with the PCN.

Differences between respondents with and without formal health training were not statistically significant for naming of the most effective treatments for malaria, diarrhoea, or pneumonia, or stocking of ACT, ORS, or amoxicillin.

\section{Multivariate analyses of the correlates of knowledge and stocking of most effective treatments}

In multivariate analysis (Table 2), characteristics associated with having higher odds of correctly naming the most effective treatment for malaria included residing in Kogi state (OR $=4.093 ; 95 \%$ CI 1.711-9.793), being a PCN member $(\mathrm{OR}=3.181 ; 95 \%$ CI 1.165-8.685), selling drugs wholesale $(\mathrm{OR}=4.230 ; 95 \% \mathrm{CI} 1.351-13.680)$, and having participated in any trainings in the previous year $(\mathrm{OR}=2.397 ; 95 \%$ CI 1.135 - 5.060). No PPMV characteristics were significantly associated with stocking ACTs. State was the only characteristic associated with naming the most effective treatment for diarrhoea (Table 3): respondents in Kogi were significantly less likely to identify ORS than those in Kwara $(\mathrm{OR}=0.240$; $95 \%$ CI 0.104 - 0.555). Respondents with formal health training were significantly more likely to stock ORS than those without health training $(\mathrm{OR}=2.625$; $95 \%$ CI 1.103 - 6.802). No other covariates significantly predicted stocking of ORS. Paediatric formulations of amoxicillin are not available in Nigeria; therefore, any reported amoxicillin stocking, which is against current PPMV regulations, is for adult formulations. For this reason, further analysis of this outcomes was excluded.

\section{Discussion}

Drug retailers, such as PPMVs, provide a majority of drugs to treat childhood illnesses in low- and middle-income countries and have the potential to contribute to advancing child health. However, this and other studies [12, 19, 26] have indicated that PPMVs do not always properly treat common childhood illnesses. In Kogi and Kwara states, about $75 \%$ of shops stocked ORS and ACT, the majority of shops offered amoxicillin contrary to current regulations, and those stocking zinc were minimal.

The results also indicate that although many PPMVs stock treatments for pneumonia, diarrhoea, and malaria, knowledge of the most effective treatment is lower. Moreover, having formal health training was not significantly associated with naming the most effective treatments for malaria or diarrhoea in multivariate analyses, and was only statistically related to stocking of ORS. Hence, even 
Table 1 PPMV Shop characteristics (Source: Shop survey) ${ }^{a}$

\begin{tabular}{|c|c|c|c|}
\hline & Health training $\mathrm{n}(\%)$ & No health training (\%) & $p$-value \\
\hline \multicolumn{4}{|l|}{ Knowledge of shop workers and owners } \\
\hline Named most effective treatment for malaria & $39(73.6)$ & $135(68.5)$ & \\
\hline Named most effective treatment for diarrhoea & $15(32.0)$ & $63(28.3)$ & \\
\hline Named most effective treatment for pneumonia & $0(0.0 \%)$ & $1(0.5 \%)$ & \\
\hline \multicolumn{4}{|l|}{ Drug stocking ${ }^{b}$} \\
\hline Stocked $A C T^{\complement}$ for malaria treatment & $38(71.7)$ & $144(73.9)$ & \\
\hline Stocked ORS ${ }^{d}$ for diarrhoea treatment & $45(84.9)$ & $146(74.9)$ & \\
\hline \multicolumn{4}{|l|}{ State } \\
\hline Kogi & $21(39.6)$ & $103(52.3)$ & \\
\hline Kwara & $32(60.4)$ & $94(47.7)$ & \\
\hline \multicolumn{4}{|l|}{ Location } \\
\hline Urban & $11(20.8)$ & $59(30.0)$ & \\
\hline Peri-urban & $17(32.1)$ & $68(34.5)$ & \\
\hline Rural & $25(47.2)$ & $70(35.5)$ & \\
\hline Male respondents ${ }^{\mathrm{e}}$ & $28(52.8)$ & $117(60.3)$ & \\
\hline Age of respondent ${ }^{\mathrm{b}}$ mean $\pm \mathrm{SD}$ (years) & $40.0 \pm 1.7$ & $31.0 \pm 7.5$ & 0.000 \\
\hline \multicolumn{4}{|l|}{ Religion $^{a}$} \\
\hline Christian & $36(67.9)$ & $115(59.0)$ & \\
\hline Muslim & $17(32.1)$ & $80(41.0)$ & \\
\hline Education & & & 0.000 \\
\hline Primary & $1(1.9)$ & $12(6.1)$ & \\
\hline Secondary & $2(3.8)$ & $139(70.6)$ & \\
\hline Post-secondary & $50(94.3)$ & $46(23.4)$ & \\
\hline \multicolumn{4}{|l|}{ Profession/Formal health training ${ }^{b}$} \\
\hline Current PPMV apprentice or no training & - & $57(32.3)$ & \\
\hline Finished PPMV apprentice & - & $132(67.7)$ & \\
\hline $\mathrm{CHEW}^{\mathrm{f}}$ & $28(52.8)$ & - & \\
\hline Laboratory technician & $4(7.6)$ & - & \\
\hline Pharmacist & $3(5.7)$ & - & \\
\hline Nurse or midwife & $18(34.0)$ & - & \\
\hline Mean years of experience working at a PPMV shop ${ }^{b}$ & $16.7 \pm 1.6$ & $10.5 \pm 0.6$ & 0.000 \\
\hline \multicolumn{4}{|l|}{ Proportion of household income from PPMV shop } \\
\hline Half or less & $30(56.6)$ & $89(45.2)$ & \\
\hline More than half & $23(43.4)$ & $108(54.8)$ & \\
\hline Shop sells wholesale drugs ${ }^{9}$ & $8(15.1)$ & $37(18.9)$ & \\
\hline Member of PCN & $11(20.8)$ & $35(17.8)$ & \\
\hline Shop offers tests or examinations to customers & $28(52.8 \%)$ & $59(30.3 \%)$ & 0.002 \\
\hline Participated in any trainings in past 12 months & $36(69.2 \%)$ & $124(66.3 \%)$ & \\
\hline Number of observations & 53 & 197 & \\
\hline
\end{tabular}

${ }^{\mathrm{a}}$ Patent and Proprietary Medicine Vendors

$\mathrm{b}_{n}=248$

$\mathrm{C}_{\text {artemisinin-based combination therapy }}$

${ }^{d}$ oral rehydration solution

$\mathrm{e}_{n=247}$

${ }^{\mathrm{f}}$ community health extension worker

${ }^{g} n=249$ 
Table 2 Multivariable logistic regression of the likelihood of the PPMV's knowledge and stocking of most effective treatments for malaria. (Source: Shop survey)

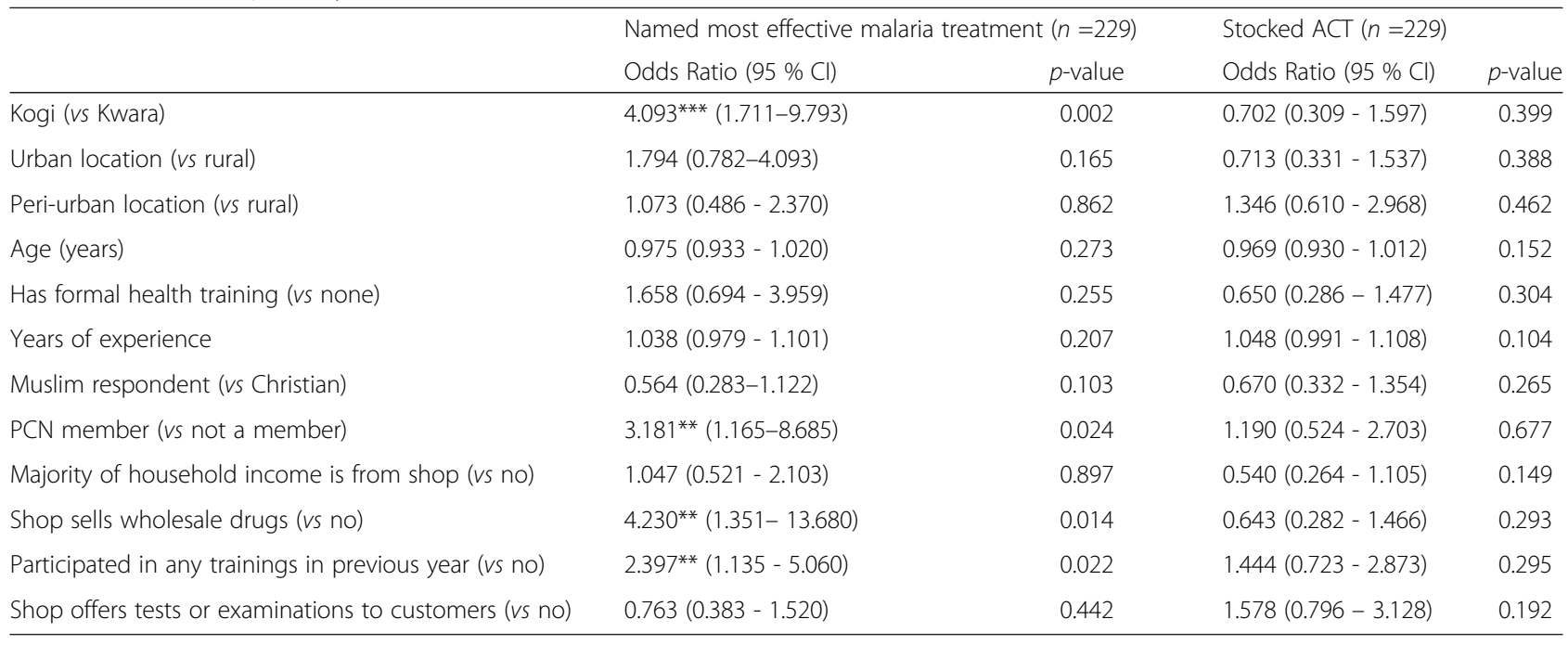

though some PPMVs have formal health training, it does not consistently relate to increased knowledge of optimal treatment or stocking behaviour. For PPMVs to be engaged in delivering iCCM, further training is needed to increase basic health knowledge and improve stocking and selling practices. Further research should be undertaken to identify optimal training methods to increase PPMV knowledge.

These findings corroborate other reports that PPMVs sell a range of medicines beyond their scope of service, including antibiotics [11, 27, 28], yet under-stock low-demand products [23]. Concerted campaigns to increase awareness of prompt treatment for malaria in combination with supply-side drug subsidies have bolstered the sales of ACTs and resulted in a higher proportion of shops stocking ACTs across Nigeria [20, 29]. Broader customer demand and awareness of the correct treatments for other paediatric illnesses are needed to reinforce optimal PPMV stocking and selling behaviours. For example, caregiver knowledge of symptoms and treatment for diarrhoea remains low [23, 30], and a similar campaign to generate demand for proper care-seeking and treatment from qualified and trained providers is needed in concert with increased zinc supply at PPMVs.

Current efforts to implement iCCM in Nigeria must consider these factors in advance of programme scale-up. In particular, according to the current implementation

Table 3 Multivariable logistic regression of the likelihood of the PPMV's knowledge and stocking of most effective treatments for diarrhoea. (Source: Shop survey)

\begin{tabular}{|c|c|c|c|c|}
\hline & \multicolumn{2}{|c|}{ Named most effective diarrhoea treatment $(n=229)$} & \multicolumn{2}{|l|}{ Stocked ORS $(n=229)$} \\
\hline & Odds ratio $(95 \% \mathrm{Cl})$ & $p$-value & Odds ratio $(95 \% \mathrm{Cl})$ & $p$-value \\
\hline Kogi (vs Kwara) & $0.240^{* * *}(0.104-0.555)$ & 0.001 & $1.524(0.655-3.544)$ & 0.328 \\
\hline Urban location (vs rural) & $0.844(0.376-1.893)$ & 0.681 & $1.237(0.549-2.791)$ & 0.608 \\
\hline Peri-urban location (vs rural) & $1.272(0.598-2.705)$ & 0.532 & $1.093(0.493-2.424)$ & 0.827 \\
\hline Male (vs female) & $0.563(0.258-1.228)$ & 0.149 & $0.783(0.346-1.771)$ & 0.556 \\
\hline Age (years) & $1.004(0.961-1.049)$ & 0.862 & $0.966(0.925-1.009)$ & 0.118 \\
\hline Has formal health training (vs no) & $0.551(0.237-1.279)$ & 0.165 & $2.625^{* *}(1.013-6.802)$ & 0.047 \\
\hline Years of experience & $0.996(0.942-1.053)$ & 0.888 & $1.017(0.960-1.078)$ & 0.565 \\
\hline Muslim respondent (vs Christian) & $0.836(0.420-1.664)$ & 0.609 & $0.613(0.305-1.229)$ & 0.168 \\
\hline PCN member (vs no) & $1.690(0.774-3.692)$ & 0.188 & $1.849(0.731-4.682)$ & 0.194 \\
\hline Majority of household income is from shop (vs no) & $1.143(0.573-2.279)$ & 0.704 & $1.322(0.655-2.670)$ & 0.436 \\
\hline Shop sells wholesale drugs (vs no) & $0.565(0.227-1.409)$ & 0.221 & $1.923(0.706-5.233)$ & 0.201 \\
\hline Participated in any trainings in previous year (vs no) & $1.538(0.746-3.250)$ & 0.249 & $1.253(0.608-2.582)$ & 0.540 \\
\hline Shop offers tests or examinations to customers (vs no) & $1.119(0.576-2.171)$ & 0.739 & $1.076(0.537-2.157)$ & 0.836 \\
\hline
\end{tabular}

${ }^{*} p<0.1,{ }^{* *} p<0.05,{ }^{* * *} p<0.01$ 
framework, PPMVs are eligible to become communitybased resource persons trained and certified to deliver iCCM. Elsewhere, trained community health workers have successfully participated in iCCM efforts. In Ghana and Uganda, lay community health workers trained in dosing and referral for treatment of fever and pneumonia, respectively, provided appropriate treatment for a majority of cases among children under five years of age [31,32]. In Uganda, drug retailers trained in ICCM and given diagnostic supplies and pre-packaged child formulations of ACT, amoxicillin, and ORS and zinc correctly managed childhood illnesses in $87.7 \%$ of cases [33]. This suggests that PPMVs may serve as an effective lay cadre of iCCM providers in Nigeria, if properly trained. However, current PPMV regulations are inconsistent with ICCM guidelines, which allow certified providers to treat uncomplicated diarrhoea, malaria, and pneumonia with ORS and zinc, $\mathrm{ACT}$, and amoxicillin, respectively. The prohibition of antibiotic sales at PPMVs precludes legally training them on the proper treatment of pneumonia or other bacterial infections, as well as enforcing regulatory mechanisms to ensure medicines are of high quality and properly formulated for children. While the large existing numbers of PPMVs in Nigeria could be leveraged to quickly increase access to these basic paediatric services, regulations must be harmonized with national policies and iCCM guidelines to provide PPMVs with the training necessary to effectively treat uncomplicated episodes of the most common paediatric illnesses, and recognize and refer when necessary.

Several limitations of this study should be noted. The sample of PPMVs was limited by security and logistical concerns and was not representative of the census, which may reduce the external generalizability of the paper's results. While the census indicated over half of PPMVs had formal health training, only $20 \%$ in the shop survey sample reported this. However, the trends in formal health training are consistent with the census in terms of state and location type as part of the sampling stratification. Training and other sociodemograhic characteristics are self-reported. Questionnaires were written in English and administered in several local languages, allowing for potential errors in translation. Stocking practices of essential medicines did not record which formulations were sold or whether the formulation stocked was an approved form. Despite these challenges, this paper provides the most comprehensive assessment of knowledge and stocking for the integrated treatment of childhood malaria, diarrhoea, and pneumonia at PPMVs in Nigeria to date.

\section{Conclusions}

PPMVs may provide an opportunity to improve children's health at the community level, but several challenges remain, including sub-optimal stocking and selling practices. Although PPMVs are included as implementers of iCCM under current guidelines, their role as community resource persons remains unclear. There is a need to ensure PPMVs understand how to correctly administer the essential medicines they stock through improved training mechanisms, in order to effectively increase access to quality-assured paediatric care in Nigeria.

\section{Abbreviations}

ACT: Artemisinin-based combination therapy; CHEW: Community health extension worker; iCCM: Integrated community case management; $\mathrm{MOH}$ : Ministry of health; NPC: National population commission; ORS: Oral rehydration solution; PCN: Pharmacy council of nigeria; PPMV: Patent and proprietary medicine vendor; UNICEF: United Nations children's fund; WHO: World Health Organization.

\section{Competing interests}

The authors declare no conflicts of interest. The funders had no role in the study design, data collection, analysis, decision to publish, or preparation of the manuscript. $\mathrm{Cl}$, the corresponding author, confirms that she had full access to all the data in the study and had final responsibility for the decision to submit for publication.

\section{Authors' contributions}

$J$ conceived of the overall study. $J$ and ET designed the analytical approach and hypotheses. ET conducted the analysis and wrote the manuscript. LMP provided assistance in writing the manuscript. Cl provided technical assistance in study execution and assistance in writing the manuscript. All authors read and approved the final manuscript.

\section{Acknowledgements}

The authors wish to acknowledge the Bill and Melinda Gates Foundation for financial support of this study. All opinions expressed are those of the authors and not the funding agency. The authors are grateful to Maia Sieverding and Naomi Beyeler for their assistance in study design, and to Nadia Diamond-Smith for feedback on manuscript drafts. We would also like to acknowledge the excellent work of the data collection team, led by Adetunji Ilori, Adepeju Akinrinlewo, David Segun Ayinde, Ibrahim Abubakar, and Sunday Erhiwieta.

\section{Author details}

Global Health Sciences, University of California, San Francisco, 550 16th Street, Mission Hall, Global Health \& Clinical Sciences Building, San Francisco, CA 94158, USA. '2Department of Social and Behavioral Sciences, University of California, San Francisco, 3333 California St., Suite 455, San Francisco, CA 94143, USA. ${ }^{3}$ Society for Family Health, No. 8 Port Harcourt Crescent, Area 11, Garki, Abuja, Nigeria.

Received: 11 March 2015 Accepted: 22 May 2015

Published online: 04 June 2015

\section{References}

1. Black RE, Cousens S, Johnson HL, Lawn JE, Rudan I, Bassani DG, et al. Global, regional, and national causes of child mortality in 2008: a systematic analysis. Lancet. 2010:375:1969-87.

2. Jones G, Steketee RW, Black RE, Bhutta ZA, Morris SS, Bellagio Child Survival Study Group. How many child deaths can we prevent this year? Lancet. 2003;362:65-71.

3. WHO. Revised WHO classification and treatment of childhood pneumonia at health facilities: evidence summaries. Geneva: World Health Organization; 2014. http://apps.who.int/iris/bitstream/10665/137319/1/9789241507813_eng.pdf

4. WHO. Guidelines for the treatment of malaria. 2nd ed. Geneva: World Health Organization; 2010. http://whqlibdoc.who.int/publications/2010/ 9789241547925_eng.pdf.

5. Nigeria Federal Ministry of Health. Draft essential medicines scale-up plan. Abuja, Nigeria; 2009.

6. WHO. Diarrhoea: Why children are still dying and what can be done. New York: UNICEF/World Health Organization; 2009. http://www.who.int/ maternal_child_adolescent/documents/9789241598415/en/. 
7. Nigeria Federal Ministry of Health. National implementation guidelines for integrated community case management of childhood illness in Nigeria. Abuja, Nigeria; 2012

8. Berendes S, Heywood P, Oliver S, Garner P. Quality of private and public ambulatory health care in low and middle income countries: systematic review of comparative studies. PLoS One. 2011:8:e1000433.

9. Nwaneri DU, Mmeremikwu MM, Nwaneri AC, Ibadin MO. Impact of health workshop on knowledge of malaria and anti-malaria drug prescription by patent medicine vendors in Southern Calabar District, Nigeria. J Med Biomed Res. 2013:12:139-49.

10. Nigerian National Population Commission and ICF International. Nigeria Demographic and Health Survey 2013. Abuja, Nigeria, and Rockville, MD, USA; 2014.

11. Barnes J, Chandani T, Feeley R. Nigeria Private Sector Health Assessment. Bethesda, MD, USA: PSP-One and Abt Associates; 2008. http://www.popline.org/ node/214666.

12. Akuse RM, Eseigbe EE, Ahmed A, Brieger WR. Patent medicine vendors: How can they help control malaria? Malar Res Treat. 2010;7:470754.

13. Okeke TA, Okeibunor JC. Rural-urban differences in health-seeking for the treatment of childhood malaria in south-east Nigeria. Health Policy. 2010;95:62-8.

14. Brieger WR, Osamor PE, Salami KK, Oladepo O, Otusanya SA. Interactions between patent medicine vendors and customers in urban and rural Nigeria. Health Policy Plan. 2004;19:177-82.

15. Aniebue PN, Aguwa EN, Obi El. Universal precautions: awareness and practice of patent medicines vendors in Enugu Metropolis, Southeast Nigeria. Nigerian Med J. 2010;51:30-4.

16. Uzochukwu BSC, Onwujekwe OE, Okwuosa C, Ogochukwu PI. Patent medicine dealers and irrational use of medicines in children: The economic cost and implications for reducing childhood mortality in Southeast Nigeria. PLoS One. 2014;9:e91667.

17. Nigeria Federal Ministry of Health. Essential medicine list, 5th revision. Abuja Nigeria; 2010

18. Okeke TA, Uzochukwu BS, Okafor HU. An in-depth study of patent medicine sellers' perspectives on malaria in a rural Nigerian community. Malar J. 2006;5:97.

19. Okeke TA, Uzochukwu BS. Improving childhood malaria treatment and referral practices by training patent medicine vendors in rural South-east Nigeria. Malar J. 2009;8:260

20. ACTwatch Group. ACTwatch outlet survey report 2011, round 3: endline outlet survey report for the independent evaluation of phase 1 of the affordable medicines facility - malaria (AMFm). Abuja, Nigeria: Society for Family Health/Nigeria, Independent Evaluation Team; 2012. http://www.actwatch.info/ countries/nigeria/outlet-reports/2011.

21. Berendes S, Adeyemi O, Oladele EA, Oresanya OB, Okoh F, Valadez JJ. Are patent medicine vendors effective agents in malaria control? Using lot quality assurance sampling to assess quality of practice in Jigawa, Nigeria. PLoS One. 2012;7:e44775.

22. Rusk A, Smith N, Menya D, Obala A, Simiyu C, Khwa-Otsyula, et al. Does anti-malarial drug knowledge predict anti-malarial dispensing practice in drug outlets? A survey of medicine retailers in western Kenya. Malar J. 2012;11:263.

23. Ogunrinde OG, Raji T, Owolabi OA, Anigo KM. Knowledge, attitude and practice of home management of childhood diarrhoea among caregivers of under-5 children with diarrhoeal disease in Northwestern Nigeria. J Trop Ped. 2012:58:143-6.

24. Beyeler N, Liu J, Sieverding M. A systematic review of the role of proprietary and patent medicine vendors in healthcare provision in Nigeria. PLoS One. 2015;10:e0117165

25. Brieger WR, Salako LA, Umeh RE, Agomo PU, Afolabi BM, Adeneye AK. Promoting prepackaged drugs for prompt and appropriate treatment of febrile illnesses in rural Nigerian communities. Int Quart Community Health Educ. 2001:21:19-40.

26. Ajayi IO, Falade CO, Adeniyi JD, Bolaji MO. The role of patent medicine sellers in home management of childhood malaria: A situational analysis of experience in rural Nigeria. Int Quart Community Health Educ. 2002;21:271-81.

27. Aguwa EN, Aniebue PN, Obi IE. Management of childhood diarrhea by patent medicine vendors in Enugu North Local Government Area, South-East Nigeria. Int J Med Sci. 2010:2:88-93.

28. Okonkwo AD, Okonkwo UP. Patent medicine vendors, community pharmacists and STI management in Abuja, Nigeria. Afr Health Sci. 2010;10:253-65.
29. ACTwatch Group. Outlet survey report 2009 for the baseline independent evaluation of the affordable medicines facility (AMFm), Nigeria. Abuja, Nigeria: Society for Family Health/Nigeria, Independent Evaluation Team 2009. http://www.actwatch.info/countries/nigeria/outlet-reports/2009.

30. Bedford KJA, Sharkey AB. Local barriers and solutions to improve care-seeking for childhood pneumonia, diarrhea and malaria in Kenya, Nigeria and Niger: a qualitative study. PLoS One. 2014;9:e3100038.

31. Chinbuah MA, Abbey M, Kager PA, Gyapong M, Nonvignon J, Ashitey P, et al. Assessment of the adherence of community health workers to dosing and referral guidelines for the management of fever in children under 5 years: a study in Dangme West District, Ghana. Int Health. 2013;5:148-56.

32. Kalyango JN, Alfven T, Peterson S, Mugenyi K, Karamagi C, Rutebemberwa E. Integrated community case management of malaria and pneumonia increases prompt and appropriate treatment for pneumonia symptoms in children under five years in Eastern Uganda. Malar J. 2013;12:340.

33. Awor P, Wamani H, Tylleskar T, Jagoe G, Peterson S. Increased access to care and appropriateness of treatment at private sector drug shops with integrated management of malaria, pneumonia and diarrhoea: a quasi-experimental study in Uganda. PLoS One. 2014;9:e115440.

\section{Submit your next manuscript to BioMed Central and take full advantage of:}

- Convenient online submission

- Thorough peer review

- No space constraints or color figure charges

- Immediate publication on acceptance

- Inclusion in PubMed, CAS, Scopus and Google Scholar

- Research which is freely available for redistribution 